\title{
WHAT ARE THE REACTIVITIES OF CORONARY ARTERIES HARVESTED FROM THE HEARTS EXPOSED TO COLD ISCHEMIC PRESERVATION?
}

\author{
Caner Arslan' ${ }^{1}$,Sibel Özyazgan², Kazım Beşirli ${ }^{1}$, Emir Cantürk ${ }^{1}$, Gökçe Şirin ${ }^{1}$, Kürşat Bozkurt ${ }^{1}$, Gökhan Akkan² \\ University of Istanbul, Cerrahpaşa Medical Faculty, Turkey: Department of Cardiovascular Surgery ${ }^{1}$, Department of \\ Pharmacology ${ }^{2}$
}

Summary: This study was designed to determine the effects of pretransplant ischemic hypothermic period on reactivities of major coronary arteries. Eleven pigs were used. Right, left anterior descending and circumflex coronary arteries harvested from 6 pigs following single dose of cardioplegia and cardiectomy. The same procedures were performed in 5 pigs after 6 hours static $4{ }^{\circ} \mathrm{C}$ hypothermic preservation of the hearts. Strips prepared from these 3 coronary arteries were placed in organ chambers and contractions with acetylcholine and histamine and KCL and dilatations with noradrenaline following submaximal contractions with acetylcholine and histamine were documented. There was no statistically significant difference between results taken from both groups. The pretransplant period (until 6 hours) does not cause important differences on the reactivities of coronary arteries.

Key words: Porcine coronary artery; Transplantation.

\section{Introduction}

Today heart transplantation is one of the frequently performed surgical procedures. Donor shortage, pretransplant ischemic time and after transplantation immune reactions, heart failure, coronary vasculopathy are the major drawbacks of this procedure. Here, we focused on how pretransplant ischemic period effects reactivities of coronary arteries.

\section{Material and Methods}

In this study, 11 home pigs were used. Their weights were ranging from 12 to $16 \mathrm{~kg}$. Feeding was ceased 12 hours before the operation. The pigs were sedatized by intramuscular injection of $2 \mathrm{mg} / \mathrm{kg}$ xylazine hydrochloride and $0.5 \mathrm{mg} / \mathrm{kg}$ midazolam 15 minutes before operation. Then full sedation was made by intramuscular $20 \mathrm{mg} / \mathrm{kg}$ ketamine hydrochloride injection. After insertion of 22 no silastic venous cannula, deep anesthesia was made by intravenous injection of half of the initial doses of xylazine and ketamine ${ }^{(3)}$. Then the pigs were intubated 4.5 no tube and ventilated 12 times in a minute and tidal volume was $10-15$ $\mathrm{ml} / \mathrm{kg}$ at $40 \% \mathrm{FiO}_{2}$. Median sternotomy was made and pericardium was opened. After 400 unite $/ \mathrm{kg}$ heparine was given from the right atrium, superior vena cava (SVC) and inferior vena cava (IVC) were occluded. After 4 cardiac cycle, ascending aorta was clamped and $10 \mathrm{ml} / \mathrm{kg}$ crystalloid cardiplegia solution (Plegisol) at $4{ }^{\circ} \mathrm{C}$ was infused into the aortic root at the pressure of $150 \mathrm{mmHg}$. At the same time, right superior pulmonary vein partially excised to decompress the heart chambers and cold isotonique at $4{ }^{\circ} \mathrm{C}$ was poured into the pericardium for topical cooling. The heart was extirpated from the pericardial cavity just after cardiplegia and heart stop. Proximal $1.5 \mathrm{~cm}$ part of the left anterior descending coronary (LAD), circumflex (CX) and right coronary arteries (RCA) were harvested from the heart. This procedure was made just after the hearts were extracted from the pericardium in 6 pigs, in other 5 pigs after 6-hour cold ischemic preservation at $4{ }^{\circ} \mathrm{C}$.

Coronary artery segments were put into Krebs-ringer solution, after cleaning from soft tissues. Rings $3 \mathrm{~mm}$ in width were prepared from those arteries and they were opened and longitudinal arterial strips were obtained. These strips were inserted into the organ chambers filled with Krebs-ringer solution aerated with carbojen $\left(95 \% \mathrm{O}_{2}\right.$ and $5 \%$ $\mathrm{CO}_{2)}$ at $37{ }^{\circ} \mathrm{C}$ and their one end were connected to isometric force displacement transducer of TDA 97 polygraph.

During first 90 minutes, 5 gr stress was applied to the strips for balance and every 20 minutes solution was changed. At the end of the experiment, wet weight (w.w.) of every strip was measured. Contractions and relaxations of coronary artery strips were calculated as mg stress per mg w.w. by the soft ware of TDA 97 polygraph at computer connected to the organ chamber and simultaneous contractions and relaxation graphics were drawn. From these 
graphics, $\mathrm{pD}_{2}$ (- Log EC50) values (sensitivity) which is the negative logarithm of half value maximum reaction and also maximum contraction and maximum relaxation values were calculated. Concentration-contraction graphics were obtained from cumulative addition of acetylcholine (Ach) $\left(10^{-9}, 3 \times 10^{-9}, 10^{-8}, 3 \times 10^{-8}, 10^{-7}, 3 \times 10^{-7}, 10^{-6}, 3 \times 10^{-6}, 10^{-5}, 3 \times 10^{-5}\right.$, $10^{-4} \mathrm{mM}^{)}$and histamine (His) $\left(6 \times 10^{-6}, 3 \times 10^{-6}, 10^{-6}, 6 \times 10^{-5}\right.$, $\left.3 \times 10^{-5}, 10^{-5}, 6 \times 10^{-4}, 3 \times 10^{-4}, 10^{-4} \mathrm{mM}\right)$ and $\mathrm{KCL}(20,40,60$, $80 \mathrm{mM}$ ) until the maximum reaction was taken after balance period. The second dose of drug was not given before contraction reached a plato from the first dose of drug. Relaxation graphics were obtained from the arterial strips contracted with submaximal (EC 90) Ach and His by cumulative addition of noradrenalin (NA) $\left(10^{-9}, 3 \times 10^{-9}, 10^{-8}\right.$, $3 \times 10^{-8}, 10^{-7}, 3 \times 10^{-7}, 10^{-6}, 3 \times 10^{-6}, 10^{-5}, 3 \times 10^{-5}, 10^{-4} \mathrm{mM}$ ). From these graphics percent inhibition of relaxation for NA and $\mathrm{pD}_{2}$ values were calculated. Again the second dose of drug was not given before relaxation caused by previous one had reached a plato. Before every medication, 45 minutes rest periods were taken and during these times strips were washed in every 15 minutes.

For statistical analysis between groups, one way ANOVA and post hoc Tukey-Kramer HSD tests were used and $\mathrm{p}<0.05$ was set for significance.

\section{Results}

There is no statistically significant difference between two groups in $\mathrm{pD}_{2}$ values of contraction reactions to cumulative Ach, His and KCL of LAD, CX and RCAs taken from the 6 pigs in the first group and 5 pigs in the second group (Tab. 1).

Tab. 1: Mean and standard deviations of $\mathrm{pD}_{2}$ values of Ach, His and KCL contraction reactions of RCA, CX and LAD from 6 pigs in the first group and 5 pigs in the second group.

\begin{tabular}{|l|c|c|c|}
\hline & RCA & CX & LAD \\
\hline $1^{\text {st }}$ group Ach & $6.23 \pm 0.09$ & $6.15 \pm 0.17$ & $6.36 \pm 0.25$ \\
\hline $2^{\text {nd }}$ group Ach & $6.21 \pm 0.11$ & $6.30 \pm 0.13$ & $5.99 \pm 0.08$ \\
\hline $1^{\text {st }}$ group His & $3.40 \pm 0.32$ & $3.70 \pm 0.16$ & $3.62 \pm 0.10$ \\
\hline $2^{\text {nd }}$ group His & $3.71 \pm 0.07$ & $3.62 \pm 0.16$ & $3.49 \pm 0.14$ \\
\hline $1^{\text {st }}$ group KCL & $1.58 \pm 0.03$ & $1.66 \pm 0.08$ & $1.73 \pm 0.04$ \\
\hline $2^{\text {nd }}$ group KCL & $1.44 \pm 0.10$ & $1.47 \pm 0.04$ & $1.55 \pm 0.03$ \\
\hline
\end{tabular}

Tab. 2: Mean and standard deviations of $\mathrm{pD}_{2}$ values of Ach, His submaximal contraction and NA relaxation reactions of RCA, CX and LAD from 6 pigs in the first group and 5 pigs in the second group.

\begin{tabular}{|l|c|c|c|}
\hline & RCA & CX & LAD \\
\hline $1^{\text {st }}$ group Ach & $7.20 \pm 0.31$ & $7.54 \pm 0.33$ & $7.15 \pm 0.33$ \\
\hline $2^{\text {nd }}$ group Ach-NA & $6.95 \pm 0.42$ & $6.60 \pm 0.26$ & $6.73 \pm 0.17$ \\
\hline $1^{\text {st }}$ group His-NA & $7.20 \pm 0.10$ & $7.50 \pm 0.27$ & $7.36 \pm 0.29$ \\
\hline $2^{\text {nd }}$ group His-NA & $6.78 \pm 0.08$ & $6.73 \pm 0.08$ & $6.47 \pm 0.11$ \\
\hline
\end{tabular}

There is also no statistically significant difference between two groups in $\mathrm{pD}_{2}$ values of Ach, His contraction-NA relaxation reactions (Tab. 2).

Statistically significant difference is not determined between maximum contractions of LAD, CX and RCAs in the both groups to Ach, His and KCL, except maximum contractions of RCAs in two groups to Ach. The maximum contraction value of RCAs in the first group $357 \pm 180$ $\mathrm{mg} / \mathrm{mg}$ w.w. in contrast to $656 \pm 127 \mathrm{mg} / \mathrm{mg}$ w.w. in the second group.

\section{Discussion}

In this study, we used single dose cardioplegia and static hypothermic preservation. LAD, CX and RCAs were harvested immediately after cardioplegia in one group and 6 hours later which is the maximum safe period for static hypothermic preservation in the heart transplantation in the other group. We didn't compose additional groups by making endothelial injury in the coronary artery strips because we were interested in the effects of pretransplant time loss.

A prominent decrease was determined in nitric oxide synthase activity in endothelial cell culture of porcine coronary arteries preserved in $4{ }^{\circ} \mathrm{C}$ University of Wisconsin solution (UWS) for 6 hours in contrast to ones preserved in $37^{\circ} \mathrm{C}$ UWS. This is a damage to the heart caused by long term hypothermic preservation (5). In contrast to this, it is shown that vascular smooth muscle and endothelium-dependent relaxations were preserved in canine coronary arteries after 24 -hour hypothermic $\left(4^{\circ} \mathrm{C}\right)$ storage in UWS in another study (6). Maximum contraction to Ach, His and KCL is related smooth muscle cell and endothelial function $(4,5)$. In our experiment, there was no meaningful difference between maximum contractions of coronary arteries in both groups except RCAs.

There was no meaningful difference between sensitivity $\left(\mathrm{pD}_{2}\right)$ values of contraction reactions to Ach, His and KCL and relaxation reactions to NA of contracted coronary arteries by Ach and His in both groups. It is seen that there is no serious difference in functions of endothelium and smooth muscle of coronary arteries taken from the hearts immediately after harvesting and the hearts preserved for 6 hours at static hypothermia $\left(4^{\circ} \mathrm{C}\right)$.

It can be said that pretransplant static hypothermic preservation time does not effect posttransplant myocardial performance by effecting coronary arteries. Regression of endothelial dysfunction occurring early after transplantation shows episodic nature of immune injury (1). Endothelial dysfunction is common in the early period after transplantation. Early constrictor response of coronary arteries to achetylcholine can be accepted as a sign of intimal injury. By intracoronary ultrasonography, one year after transplantation, a significant increase is found in the intimal thickness of coronary artery segments which con- 
tracts to early posttransplant intracoronary injection of acetylcholine (2).

Here, significant difference between sensitivity $\left(\mathrm{pD}_{2}\right)$ values of contraction reactions of coronary arteries to Ach in both groups is not determined. This supports that length pretransplant ischemic hypothermic period is not effective in the etiology of posttransplant intimal thickness and atherosclerosis.

\section{Conclusions}

Absence of meaningful differences in reactivities of coronary arteries in both groups points that endothelial and smooth muscle cell injury originates from delivery of cardioplegia not from the static hypothermic preservation period. We can also conclude that pretransplant period until 6 hours cannot play any role in the development of posttransplant vasculopathy.

\section{Acknowledgements}

This study was financially supported by Istanbul University Research Foundation. We are grateful to Professor Tuncay Altug who is the chief of Research Animal Laboratory in Cerrahpaşa Medical Faculty and Dr. Nurten Öcalan from the same institution for their great help.

\section{References}

1. Anderson TJ, Meredith IT,Uehata A, Mudge GH, Selwyn AP, Ganz P et al. Functional significance of intimal thickening as detected by intravascular ultrasound early and late cardiac transplantation. Circulation 1993;88: 1093-100.

2. Davis SF, Yeung AC, Meredith IT et al. Early coronary dysfunction predicts the development of transplant coronary artery disease at 1 year posttransplant. Circulation 1996;93:457-62.

3. Harvey RC, Walber J. Special considerations for anesthesia and Analgesia in research animals. In: Short CE ed. Principles and Practice of Veterinary Anesthesia. Edinburg: Williams and Wilkins, 1987:380-92.

4. Lin PJ, Chang CH, Yao PC, Liu HP, Hsieh HC, Tsai KT. Enhancement of endothelium dependent contraction of the canine coronary artery by UW solution. Transplantation 1994;58:1323-8.

5. Redondo J, Manso MA, Pacheco ME, Hernandez L, Salaices M, Marin J. Hypothermic storage of coronary endothelial cells reduces nitric oxide synthase activity. Cryobiology 2000;4:292-300

6. Sorajja P, Cable DG, Schaff HV. Hypothermic storage with University of Wisconsin solution preserves endothelial and vascular smooth muscle cell function. Circulation 1997;96(suppl 9):297-303.

Submitted February 2004.

Accepted July 2004.

Dr. Caner Arslan, TDV, 29 Mayis Hastanesi, Kalp ve Damar Cerrahisi Kliniği, Emniyet müdürlüğ̈̈ yant, Vatan cd. Kanlı çıkmazı sk. 34250, Fatih/Istanbul - Turkey. e-mail: canerkvc@yahoo.com 